\title{
Retrospective assessment of liver cell proliferation via PCNA: a comparison with tritiated thymidine
}

\author{
Daniel R. Dietrich*a ${ }^{*}$ Regula Candrian ${ }^{a}$, Daniel S. Marsman ${ }^{\text {b,c }}$, James A. Popp ${ }^{\text {b,d }}$, \\ William K. Kaufmann ${ }^{e}$, James A. Swenberg ${ }^{e, f}$ \\ "Institute of Toxicology ETH and University of Zuerich, Schorenstr, 16, CH-8603 Schwerzenbach, Switzerland \\ ${ }^{b}$ Chemical Industry Institute of Toxicology, Research Triangle Park, NC 27709, USA \\ ${ }^{c}$ National Institute of Environmental Health Sciences, Research Triangle Park, NC 27709, USA \\ ${ }^{d}$ Sterling-Winthrop Pharmaceutical Research Division, Collegeville, PA 19426-0900, USA \\ 'Department of Pathology, University of North Carolina at Chapel Hill, Chapel Hill, NC 27514-7295, USA

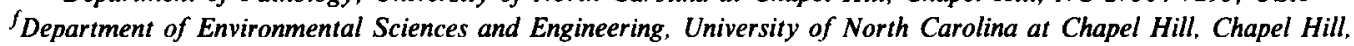 \\ NC 27514-7400, USA
}

\begin{abstract}
Cell proliferation ( $\mathrm{S}$ phase response) in archival liver tissues of partially hepatectomized rats was determined via proliferating cell nuclear antigen (PCNA) immunohistochemistry. These results were compared with the $S$ phase response assessed previously in the same tissues via tritiated thymidine (Tdr) autoradiography. The effect of prolonged tissue fixation on PCNA immunohistochemistry was compared in two studies: study A, the liver was fixed for a maximum of 7 days and then embedded in paraffin and stored for $\sim 18$ months, while in study B, the liver was fixed in formalin for 7 years and then embedded in paraffin and stored for $\sim 18$ months until sectioning and immunostaining. PCNA immunostaining was successful in the liver sections of both studies, irrespective of the length of formalin fixation. Furthermore, the S phase labeling indices (LI) determined via PCNA and Tdr were comparable, although not identical, in the two studies. Therefore, use of PCNA immunohistochemistry should allow retrospective staining of rodent tissues for the assessment of cell proliferative activity in formalin-fixed organs from previously conducted toxicity and carcinogenicity studies.
\end{abstract}

Key words: PCNA; Tritiated thymidine; Cell proliferation; Liver; Retrospective

\section{Introduction}

A variety of methods are being used today to measure cell proliferation. Of these methods, the

\footnotetext{
* Corresponding author.
}

two most established are $\left[{ }^{3} \mathrm{H}\right]$ thymidine (Tdr) autoradiography and 5-bromo-2'-deoxyuridine (BrdU) immunohistochemistry. Measurement of cell proliferation using these two methods is possible only if $\mathrm{Tdr}$ or BrdU is administered to the experimental animal prior to sacrifice. Under nor- 
mal circumstances (prospective research) this does not pose a problem. In some instances, however, pathological changes are observed in the tissue of interest long after the experiment has been completed. Interpretations of these pathological changes could be enhanced by cell proliferation measurements, but due to the lack of preadministered label (thymidine analogue) such studies cannot be evaluated using Tdr autoradiography or BrdU immunohistochemistry. On the other hand, immunohistochemical procedures have been developed using an endogenous antigen which is present in high concentrations in cells undergoing replication or DNA excision repair [7]. Furthermore, recent studies $[6,10,13]$ have shown that it is possible to detect this antigen in archival rodent tissues stored in paraffin for up to 2 years, and thus to measure cell proliferation in archival tissue. This antigen, known as proliferating cell nuclear antigen (PCNA) (see Ref. 7 for review), is a $36-\mathrm{kDa}$ acidic protein closely associated with DNA polymerase $\delta[1,2,4]$. DNA polymerase $\delta$ is essential for leading strand synthesis in DNA replication and PCNA was shown to increase processivity $[2,8,21]$. Synthesis of PCNA appears to begin in the late $G_{1}$ and to peak during the $S$ phase of the cell cycle $[3,4,18,24]$. Due to the presence of PCNA in the late $G_{1} / S$ phase, $S$ phase, $G_{2}$ phase, and during mitosis, all cells within a given tissue, with the exception of quiescent $\left(G_{0}\right)$ cells, stain positive for PCNA when analysed via immunohistochemistry [9]. Cells in the different phases of the cell cycle staining positive for PCNA can roughly be distinguished based on the difference in staining intensity $[9,10], S$ phase cells staining with the highest intensity $[6,9,10,13,15]$.

In order to effectively use this new technique for retrospective measurement of cell proliferation, it is a prerequisite that the results achieved with this new technique be comparable with those achieved with Tdr or BrdU. Most studies have compared either Tdr or BrdU with PCNA in human cell lines or freshly fixed tissue $[3,5,12,20,25]$. Celis and Celis [3] demonstrated that PCNA and Tdr labeling were comparable, if not identical, when using synchronized human cells. Similar results were reported by van Dierendonck et al. [25] when comparing PCNA with BrdU in human cell lines. Coltrera and Gown [5], on the other hand, did not find agreement between BrdU and PCNA labeling in mixed human cell cultures. These discrepancies may stem from variable PCNA-positive immunostaining. Variable staining for PCNA was also reported in freshly fixed tissue [12,15], depending on the length of fixation of the tissue and on the type of fixative chosen. Indeed, prolonged exposure to formalin or other types of fixatives is believed to result in protein cross-linking within the tissues of interest, thereby masking antigenic sites such that they cannot react with specific antibodies [13]. Thus, this effect is most likely a methodological artifact, which can heavily influence cell proliferation measurements via PCNA immunostaining.

While the length of fixation of the tissue and choice of fixative can be controlled in future studies or recapitulated with relatively high certainty in contemporary studies, this is certainly not the case for tissues reclaimed from tissue archives. However, it is just in these tissues where retrospective cell proliferation measurements via PCNA immunohistochemistry are of greatest importance. In order to understand the effects of prolonged tissue fixation or storage in paraffin on PCNA immunostaining it appeared important to compare PCNA immunostaining with $\mathrm{Tdr}$ autoradiography in the same tissues.

For this, two already completed cell proliferation studies were chosen. Both studies used partial hepatectomy and $\mathrm{Tdr}$ labeling as the means for cell proliferation induction and measurements, respectively. One study was completed in 1989 and the livers were fixed for a maximum of 7 days before embedding in paraffin. The other study was completed in 1983 and the livers were left in fixative for over 7 years and then embedded in paraffin. Thus, assuming that all other parameters of these two studies were comparable in design and methodological protocol, PCNA immunohistochemistry on sections of both studies should allow determination of how prolonged fixation can affect retrospective detection of proliferating cells.

\section{Materials and methods}

\subsection{Study A}

Animals, partial hepatectomies, and Tdr application Twelve-week-old F344 male rats were purchased 
Table 1

Study A: labeling indices (LI) obtained with PCNA staining and Tdr autoradiography and mitotic indices (MI) in liver sections of male F344 rats at varying time points after partial hepatectomy (PH)

\begin{tabular}{|c|c|c|c|c|c|c|}
\hline \multirow[t]{2}{*}{ Group } & \multirow{2}{*}{$\frac{\text { Tdr [LI (\%)] }}{\text { S phase }}$} & \multirow[t]{2}{*}{$n$} & \multicolumn{3}{|c|}{ PCNA [LI (\%)] } & \multirow{2}{*}{$\frac{\text { MI }(\%)}{\text { Mitosis }}$} \\
\hline & & & $S$ phase & $\mathrm{G}_{1}-\mathrm{S} / \mathrm{G}_{2}$ & $\mathrm{G}_{0}$ & \\
\hline $24 \mathrm{~h} \mathrm{PH}$ & $57 \pm 2$ & 3 & $71 \pm 8^{c}$ & $11 \pm 4$ & $18 \pm 6$ & $0.04 \neq 0.07$ \\
\hline $48 \mathrm{~h} \mathrm{PH}$ & $14 \pm 2^{a}$ & 3 & $22 \pm 5^{b, c}$ & $23 \pm 2$ & $51 \pm 7$ & $3.94 \pm 1.84$ \\
\hline 72 h PH & $8 \pm 5^{a}$ & 4 & $13 \pm 4^{b}$ & $26 \pm 10$ & $54 \pm 9$ & $4.14 \pm 1.14$ \\
\hline $96 \mathrm{~h} \mathrm{PH}$ & $2 \pm 1^{a}$ & 3 & $4 \pm 1^{b}$ & $31 \pm 2$ & $63 \pm 3$ & $2.36 \pm 0.29$ \\
\hline
\end{tabular}

$n$, number of liver sections available for cell proliferation measurements.

asignificantly different $(P<0.05$, one-factor ANOVA) from the 24-h Tdr data.

bSignificantly different $(P<0.05$, one-factor ANOVA) from the 24-h PCNA data.

'Significantly different $(P<0.05$, one-factor ANOVA) from the corresponding Tdr data.

from Charles River Inc. (Raleigh, NC) and acclimated in the animal holding area for a minimum of 7 days. After acclimatization, all animals were subjected to $2 / 3$ partial hepatectomy $(\mathrm{PH})$ according to the protocol published by Higgins and Anderson [16]. A minimum of three animals were killed 24, 48, 72, and $96 \mathrm{~h}$ following PH (Table 1). All rats were injected with $2 \mathrm{mCi} / \mathrm{kg}$ of $\mathrm{Tdr}$ (specific activity, $82.7 \mathrm{Ci} / \mathrm{mmol}) 2 \mathrm{~h}$ prior to sacrifice. The right lateral liver lobe of every animal was fixed in 10\% buffered formalin for 7 days, embedded in paraffin, and (i) processed immediately for autoradiography, or (ii) stored for $\sim 18$ months, then sectioned and stained for PCNA. The re- mainder of the liver was homogenized in $0.2 \%$ Triton X-100 for quantitation of Tdr uptake.

\section{Autoradiography and cell proliferation measure- ments}

The autoradiography was carried out according to the procedure described by Marsman et al. [19]. All slides were inspected at $400 \times$ magnification and nuclei containing 8 or more grains were considered labeled and in $\mathrm{S}$ phase. A minimum of 2000 hepatocytes were counted per liver and animal. The labeling index (LI) was defined as the percentage of labeled cells per total number of cells counted.

Table 2

Study B: labeling indices (LI) obtained with PCNA staining and Tdr autoradiography and mitotic indices (MI) in liver sections of male F344 rats at varying time points after partial hepatectomy $(\mathrm{PH})$

\begin{tabular}{|c|c|c|c|c|c|c|c|}
\hline \multirow[t]{2}{*}{ Group } & \multicolumn{2}{|c|}{$\operatorname{Tdr}[\mathrm{LI}(\%)]$} & \multicolumn{4}{|c|}{ PCNA [LI (\%)] } & \multirow{2}{*}{$\frac{\text { MI }(\%)}{\text { Mitosis }}$} \\
\hline & S phase & $n$ & S phase & $\mathrm{G}_{1}-\mathrm{S} / \mathrm{G}_{2}$ & $\mathrm{G}_{0}$ & $n$ & \\
\hline Control & $0.2 \pm 0.4$ & 3 & $1.2 \pm 0.4$ & $9 \pm 6$ & $89 \pm 6$ & 3 & $0.4 \pm 0.2$ \\
\hline $4 \mathrm{~h} \mathrm{PH}$ & $1.3 \pm 0.2$ & 3 & $1.8 \pm 0.9$ & $6 \pm 2$ & $91 \pm 3$ & 3 & $0.5 \pm 0.5$ \\
\hline $12 \mathrm{~h} \mathrm{PH}$ & $0.4 \pm 0.1$ & $2^{\mathrm{a}}$ & $2.4 \pm 0.9$ & $17 \pm 6$ & $81 \pm 7$ & 3 & $0.4 \pm 0.2$ \\
\hline $15 \mathrm{~h} \mathrm{PH}$ & $6 \pm 3$ & 3 & $3 \pm 1$ & $24 \pm 1$ & $74 \pm 2$ & 3 & $0.3 \pm 0.1$ \\
\hline $18 \mathrm{~h} \mathrm{PH}$ & $8 \pm 15$ & 4 & $5 \pm 2$ & $28 \pm 17$ & $67 \pm 19$ & $3^{c}$ & $0.2 \pm 0.1$ \\
\hline $21 \mathrm{~h} \mathrm{PH}$ & no label & $3^{b}$ & $7 \pm 7$ & $28 \pm 9$ & $65 \pm 15$ & $2^{c}$ & $0.3 \pm 0.1$ \\
\hline $24 \mathrm{~h} \mathrm{PH}$ & $13 \pm 2$ & 3 & $13 \pm 5$ & $32 \pm 14$ & $49 \pm 4$ & $2^{c}$ & $6.3 \pm 5.4$ \\
\hline
\end{tabular}

$n$, number of liver sections available for cell proliferation measurements.

${ }^{a}$ No data was available for one animal.

${ }^{b}$ No Tdr labeling was achieved in the original study.

${ }^{c}$ Due to faint or inadequate PCNA staining the data of one animal per group was not included. 


\subsection{Study B}

Animals, partial hepatectomies, and Tdr application

Seven-week-old F344 male rats were purchased from Charles River Inc. (Raleigh, NC) and acclimated for 1 week in the animal holding area before being subjected to $2 / 3$ partial hepatectomy. Conditions of animal surgery and postsurgical treatment were as detailed previously [17]. A minimum of 3 animals were killed 4, 12, 15, 18, 21, and $24 \mathrm{~h}$ following $\mathrm{PH}$ (Table 2). All rats were injected with $0.8 \mathrm{mCi} / \mathrm{kg}$ of $\mathrm{Tdr}$ (specific activity, 50 $\mathrm{Ci} / \mathrm{mmol}$ ) $30 \mathrm{~min}$ prior to sacrifice. The right lateral liver lobe of every animal was fixed in $10 \%$ buffered formalin for 30 days, embedded in paraffin, and processed immediately for autoradiography. The remainder of the liver was (i) homogenized for quantitation of $\mathrm{Tdr}$ uptake or (ii) stored in $10 \%$ buffered formalin for 7 years, then embedded in paraffin for $\sim 18$ months, sectioned, and stained for PCNA.

\section{Autoradiography and cell proliferation measure- ments}

The autoradiography was carried out according to the procedure described by Kaufmann et al. [17]. All slides were inspected at $400 \times$ magnification and nuclei containing 8 or more grains were considered labeled and in $\mathrm{S}$ phase. A minimum of 1500 hepatocytes were counted per liver and animal. The labeling index (LI) was defined as the percentage of labeled cells per total number of cells counted.

\subsection{PCNA immunohistochemistry, distinction of cell cycle phases, and cell proliferation} measurements

The paraffin-embedded liver samples were cut to $2-4-\mu \mathrm{m}$ thin sections and placed onto aminopropyltriethoxysilane (APTS, Sigma No. A3648; Sigma, St. Louis, MS) coated glass slides. After drying for approximately 2 days the sections were deparaffinized in xylene, and $100 \%, 95 \%$, and $70 \%$ ethanol and rehydrated in phosphate buffered saline (PBS), each step lasting $2 \times 5 \mathrm{~min}$. Thereafter, the sections were immersed in $25 \%$ Biogenex Antigen Retrieval Solution (Biogenex
No. 0900-5K; Biogenex, San Ramon, CA) [23], microwaved in a commercially available microwave at $650 \mathrm{~W}$ for $2 \times 3 \mathrm{~min}$ and left to cool for another $15 \mathrm{~min}$ while still being immersed in the antigen retrieval solution. The sections were then washed in PBS for $2 \times 5 \mathrm{~min}$. In order to 'denature' double-stranded DNA, the sections were immersed in $4 \mathrm{~N} \mathrm{HCl}$ at $37^{\circ} \mathrm{C}$ for $20 \mathrm{~min}$ and then washed in PBS for $2 \times 5$ min to neutralize the acid. Endogenous peroxidase was quenched by adding a $3 \%$ hydrogen peroxide solution to the sections for $10 \mathrm{~min}$, followed by a $2 \times 5 \mathrm{~min}$ wash with PBS. A 1:400 dilution of the primary antibody to PCNA (mouse monoclonal anti-PCNA, 19A2 clone, Biogenex No. MU206-5M; Biogenex, San Ramon, CA) was applied to the sections for a duration of $60 \mathrm{~min}$. The primary antibody was then washed off with $2 \times 5$-min rinses in PBS. A secondary antibody (Biogenex supersensitive antimouse LINK, Biogenex No. ZP000-UM) was applied at a 1:10 dilution for $40 \mathrm{~min}$. This secondary antibody is biotinylated and recognizes the primary mouse antibody. Excess secondary antibody was washed off with two consecutive 5-min rinses in PBS, after which a 1:10 dilution of a streptavidin label conjugated with hydrogen peroxidase (supersensitive Biogenex LABEL, Biogenex No. ZP000-UM) was applied to the sections for another $40 \mathrm{~min}$. Excess LABEL was rinsed off in $2 \times 5$-min washes of PBS. Chromogen, 3-amino9-ethylcarbazole (AEC), and substrate were added for $2 \times 20 \mathrm{~min}$, which stained PCNA-positive nuclei reddish-brown. Excess chromogen was washed with deionized water, and the tissue was counterstained with Mayer's hematoxylin for $2 \mathrm{~min}$. This counterstain stained PCNA negative nuclei dark blue. Due to the xylene and alcohol solubility of the chromogen and counterstain, the sections were coated with a thin layer of aqueous crystal mount (Fisher Scientific No. BM02), dried in the oven at $80^{\circ} \mathrm{C}$ for $20 \mathrm{~min}$ and then coverslipped with xylene based Permount ${ }^{\circledR} \quad$ (Fischer Scientific No. SP15-100).

In agreement with previous publications on PCNA immunostaining $[9,15,25]$, strongly stained nuclei were assumed to be in S-phase, while weakly staining nuclei were considered to belong to the $\mathrm{C}_{1}-\mathrm{S}$ or $\mathrm{G}_{2}$ and non-PCNA staining nuclei to the 
$\mathrm{G}_{0}$ population of the cell cycle, respectively. Thus, three different cell populations were counted for LI determinations: those containing S-phase, $G_{1}-S$ or $G_{2}$-phase, and $G_{0}$-phase nuclei. Mitotic figures, although showing weak cytoplasmic PCNA positive staining, were counted as a separate entity, for which the Mitotic index (MI), defined as the number of mitotic figures per total number of cells counted and expressed as a percentage of the total, was calculated.

The PCNA immunostained sections were inspected under the microscope at $400 \times$ magnification without knowledge of treatment. Labeled nuclei were counted in 8 randomly chosen $400 \times$ fields, which amounted to an average of 1100 cells per section.

\subsection{Statistics}

Differences between treatment groups and cell proliferation measurement techniques were tested for significance at the $5 \%$ confidence level $(P<$ 0.05 ) by using the one-factor ANOVA test.

\section{Results}

The results of the $\mathrm{Tdr}$ cell proliferation measurements are depicted in Tables 1 and 2. In both studies a time related change in the number of cells in $\mathrm{S}$ phase was observed, namely a gradual

Table 3

Quantitation of Tdr uptake into liver DNA (study B) at various times after $\mathrm{PH}$, expressed as counts/min per $\mu \mathrm{g}$ liver DNA

\begin{tabular}{lcl}
\hline Group & $\begin{array}{l}\text { Counts/min/ } \\
\mu \text { g liver DNA }\end{array}$ & $n$ \\
\hline Control & $0.6 \pm 0.1$ & 2 \\
$4 \mathrm{~h} \mathrm{PH}$ & $5 \pm 1$ & 3 \\
$12 \mathrm{~h} \mathrm{PH}$ & $5 \pm 1$ & 3 \\
$15 \mathrm{~h} \mathrm{PH}$ & $18 \pm 6$ & 3 \\
$18 \mathrm{~h} \mathrm{PH}$ & $110 \pm 179$ & 4 \\
$21 \mathrm{~h} \mathrm{PH}$ & $2 \pm 1$ & 3 \\
$24 \mathrm{~h} \mathrm{PH}$ & $160 \pm 61$ & 3
\end{tabular}

Values are presented as means \pm standard deviation, while $n$ depicts the number of livers available for quantitation of $\mathrm{Tdr}$ uptake. decrease and increase of S phase cells in study $A$ and $B$, respectively, with the highest response at 24 $\mathrm{h}$ PH. The total number of S phase cells determined at $24 \mathrm{~h} \mathrm{PH}$ in study B were clearly lower than those determined in study $\mathbf{A}$. This discrepancy is most likely due to differences in study design with study $B$ animals receiving lower specific activity Tdr and a shorter exposure period prior to sacrificed (study B, Table 2). Tables 2 and 3 also show one of the difficulties associated with $\mathrm{Tdr}$ pulse dosing and autoradiography, namely the lack of labeled nuclei. This may be due to lack of Tdr incorporation into liver DNA due to insufficient $\mathrm{Tdr}$ tissue distribution or faulty intraperitoneal injection, and thus, loss of one or more animals per group for cell proliferation measurements.

Clearly discernible PCNA-positive staining of nuclei in $S$ phase and in $G_{1} / S$ or $G_{2}$ phase of the cell cycle were obtained in liver tissues exposed to formalin for 7 days (Table 1, study A) and 7 years (Table 2, study B) prior to embedding in paraffin. Although the darkest staining nuclei were considered to be in $S$ phase and the weaker staining ones in $G_{1} / S$ or $G_{2}$ phase, not all sections stained consistently with the same intensity. Thus, due to this variation in staining intensity, even between sections of animals of the same group, the clear distinction between $S$ phase cells and cells in $G_{1} / S$ or $G_{2}$ phase was in some cases difficult and in others completely impossible (Table 2). However, only sections with adequate staining were used for cell proliferation measurements.

The $S$ phase LI determined in study A via PCNA immunohistochemistry were all between 1.2 and 1.7 times higher than those determined via Tdr (Table 1). These differences were significant $(P<0.05)$ for the 24- and 48-h LI only, most probably due to the high variability of the $\mathrm{LI}$ in the 72- and 96-h groups. On the other hand, in study $B$ no significant differences could be detected between the $S$ phase LI determined via PCNA and Tdr (Table 2). The rather low number of animals used for the experiment and the high variability with the groups may have prevented the detcction of statistically significant differences.

As expected, the stimulatory effect of partial hepatectomy on cell proliferation could also be 
demonstrated by the percentage of cells in $G_{0}$. In study $\mathrm{A}$ this number increased steadily with increasing time after $\mathbf{P H}$, meaning that less cells were undergoing cell division. In study B, accordingly, this number decreased with increasing time after PH. From these two studies it appears as if a maximum in the cell proliferative response was reached at $24 \mathrm{~h}$ after PH (Tables 1 and 2).

The extent of cell proliferation that was induced $24 \mathrm{~h}$ after partial hepatectomy in study $\mathrm{A}$ is typical of that shown in previous studies. In contrast, the response in study B was much lower than expected. Although no explanation can be given for this difference, PCNA immunohistochemistry agreed with $\mathrm{Tdr}$ autoradiography, suggesting that both methods were identifying the proliferative compartment.

Interestingly, while the cell proliferation timecourse described by Tdr and PCNA S phase cell measurements were comparable in both studies, it was difficult to demonstrate such a time-course for either study using the mitotic index. A lag-phase of approximately $12-24 \mathrm{~h}$ was suggested between induction of $\mathbf{S}$ phase and mitosis; however, high variability limited interpretation.

\section{Discussion}

Cell proliferation measurements in archival tissue, assessed via the PCNA immunohistochemistry method, were shown to have good agreement with prospective labeling techniques, irrespective of the length of fixation of the tissues. These findings thus corroborate earlier reports $[6,10,13]$ in which acceptable PCNA immunostaining was achieved in archival tissues. In addition, cell proliferation measurements obtained via PCNA immunohistochemistry were quantitatively comparable with those obtained using $\mathrm{Tdr}$ autoradiography. Similar findings were reported by Foley et al. $[10,11]$ in a study where cell proliferation measurements were carried out via $\mathrm{Tdr}$ autoradiography as well as with PCNA immunohistochemistry in rat liver tissues that were fixed for a short time period and then left embedded in paraffin for approximately 1.5 years, thus having a similar tissue treatment protocol as study A of this paper. However, in contrast to the results of study A, where the LI ratio PCNA/Tdr varied between 1.2 and 1.7, Foley et al. [10] did not find any significant differences between the $\mathrm{LI}$ obtained via Tdr and PCNA. Similarly Richter et al. [22] found no significant differences in LI when comparing PCNA with BrdU and Tdr in freshly fixed non-archival rat colon. On the other hand, Galand and Degraef [12] found higher numbers of PCNA than Tdr-labelled nuclei (PCNA/Tdr LI ratio, 1.69 ), in freshly fixed non-archival rat liver parenchyma, comparable with values of study A. To further confuse the situation, the PCNA and Tdr LI obtained in study $B$ were not significantly different.

There may be several reasons for these discrepancies. First, in order to compare the individual studies with one another, the animal and tissue treatment protocols should be the same. Yet the studies mentioned above varied with respect to the age of the animals, length of Tdr pulse dosing, amount of Tdr dose, and length of tissue fixation time. Second, as mentioned in the Results section, problems with cell proliferation measurements can arise from faulty $\mathrm{Tdr}$ application (study B, Table 3) or from PCNA labeling due to large variability of the staining reaction within and between groups. Finally, results from PCNA immunohistochemistry and $\mathrm{Tdr}$ autoradiography may well be comparable within the same laboratory due to consistent use of established techniques. Interlaboratory comparisons, however, as were aspired to in this paper by comparing study A with study $B$, may prove to be difficult due to differences in study design, animal and tissue treatment protocols, staining techniques, definition of $S$ phase cells, and counting of labeled cells.

In summary, both methods, Tdr and PCNA, demonstrate a comparable cell proliferative response in hepatectomized rats and it is suggested that PCNA immunohistochemistry can be used as a tool for retrospective assessment of cell proliferation in archival tissue irrespective of the length of formalin fixation.

\section{References}

I Bauer, G.A. and Burgers, P.M. (1988) The yeast analog of mammalian cyclin/proliferating cell nuclear antigen in- 
teracts with mammalian DNA polymerase delta. Proc. Natl. Acad. Sci. USA, 85, 7506-7510.

2 Bravo, R., Frank, R., Blundell, P.A. and MacDonaldBravo, H. (1987) Cyclin/PCNA is the auxiliary protein of DNA polymerase $\delta$. Nature, 326, 515-517.

3 Celis, J.E. and Celis, A. (1985) Cell cycle-dependent variations in the distribution of the nuclear protein cyclin proliferating cell nuclear antigen in cultured cells: Subdivision of S phase. Proc. Natl. Acad. Sci. USA, 82, 3262-3266.

4 Celis, J.E., Madsen, P. and Celis, A. (1987) Cyclin (PCNA, auxiliary protein of DNA polymerase delta). FEBS Lett., 220, 1-7.

5 Coltrera, M.D. and Gown, A.M. (1991) PCNA/Cyclin expression and BrdU uptake define different subpopulations in different cell lines. J. Histochem. Cytochem., 39(1), 23-30.

6 Dietrich, D.R., Marsman, D.S., Popp, J.A. and Swenberg, J.A. (1992) Retrospective assessment of liver cell proliferation: comparison of two proliferation markers, PCNA and tritiated thymidine. Toxicologist, 12 , 1007.

7 Dietrich, D.R. (1993) Toxicological and pathological applications of proliferating cell nuclear antigen (PCNA), a novel endogenous marker for cell proliferation. Crit. Rev. Toxicol., 23 (1), 77-109.

8 Downey, K.M., Tan, C-K., Andrews, D.M., Li, X. and So, A.G. (1988) Proposed roles for DNA polymerases $\alpha$ and $\delta$ at the replication fork. Cancer Cells, 6, 403-410.

9 Foley, J.F., Dietrich, D.R., Swenberg, J.A. and Maronpot, R.R. (1991) Detection and evaluation of proliferating cell nuclear antigen (PCNA) in rat tissue by an improved immunohistochemical procedure. J. Histotechnol., 14(4), 237-241.

10 Foley, J.F., Ton, T., Maronpot, R.R., Butterworth, B. and Goldsworthy, T. (1992) Detection of proliferating hepatocytes in rats: comparison of ${ }^{3} \mathrm{H}$ thymidine $\left({ }^{3} \mathrm{H}\right.$ $\mathrm{Tdr})$ versus proliferating cell nuclear antigen. Toxicologist, 12, 1009.

11 Foley, J., Ton, T., Maronpot, R.R., Butterworth, B. and Goldsworthy, T.L. (in press) Proliferating cell nuclear antigen (PCNA): comparison to tritiated thymidine $\left(\left[{ }^{3} \mathrm{H}\right]-\mathrm{Tdr}\right)$ as a marker of proliferating hepatocytes in rats, Env. Health Persp.

12 Galand, P. and Degraef, C. (1989) Cyclin/PCNA immunostaining as an alternative to tritiated thymidine pulse labeling for marking S-phase cells in paraffin sections from animal and human tissues. Cell Tissue Kinet., 22, 383-392.

13 Greenwell, A., Foley, J.F. and Maronpot, R.R. (1991) An enhancement method for immunohistochemical staining of proliferating cell nuclear antigen in archival rodent tissues. Cancer Lett., 59, 251-256.

14 Greenwell, A., Foley, J.F. and Maronpot, R.R. (1992) Proliferating cell nuclear antigen immunohistochemistry: an enhanced method for archival rodent tissue. Toxicologist, 12(1), 1008.

15 Hall, P.A., Levinson, D.A., Woods, A.L., Yu, C.C.W., Kellock, D.B., Watkins, J.A., Barnes, D.M., Gillett, C.E., Camplejohn, R., Dover, R., Waseem, N.H. and Lane, D.P. (1990) Proliferating cell nuclear antigen (PCNA) immunolocalization in paraffin sections: an index of cell proliferation with evidence of deregulated expression in some neoplasms. J. Pathol., 162, 285-294.

16 Higgins, G.M. and Anderson, R.M. (1931) Experimental pathology of the liver. I. Restoration of the liver of the white rat following partial surgical removal. Arch. Pathol., 12, 186-202.

17 Kaufmann, W.K., Kaufman, D.G., Rice, J.M. and Wenk, M.L. (1981) Reversible inhibition of rat hepatocyte proliferation by hydrocortisone and its effect on cell cycledependent hepatocarcinogenesis by $N$-methyl- $N$ nitrosourea. Cancer Res., 41, 4653-4660.

18 Kurki, P., Vanderlaan, M., Dolbearer, F., Gray, J. and Tan, E.M. (1986) Expression of proliferating cell nuclear antigen (PCNA/cyclin) during the cell cycle. Exp. Cell. Res., 166, 209-219.

19 Marsman, D.S., Cattley, R.C., Conway, J.G. and Popp, J.A. (1988) Relationship of hepatic peroxisome proliferation and replicative DNA synthesis to the hepatocarcinogenicity of the peroxisome proliferators di(2ethylhexyl)phthalate and [4-chloro-6-(2,3-xylidino-)-2pyrimidinylthiolacetic acid (Wy-14,643) in rats. Cancer Res., 48, 6739-6744.

20 Nakamura, J., Dietrich, D.R, and Swenberg, J.A. (1992) Age-related changes in cell proliferation in rat liver and kidney. Toxicologist, 12, 1014.

21 Prelich, G., Tan, C-K., Kostura, M., Mathews, M.B., So, A.G., Downey, K.M. and Stillman, B. (1987) Functional identity of proliferating cell nuclear antigen and DNA polymerase $\delta$ auxiliary protein. Nature, 326, 517-520.

22 Richter, F., Richter, A., Yang, K. and Lipkin, M. (1991) Cell proliferation in rat colon measured with BrdU, PCNA, and $\left[{ }^{3} \mathrm{H}\right] \mathrm{d}$ Thd, Proc. Am. Assoc. Cancer Res., $32,154$.

23 Shi, S.-R., Key, M.E. and Kalra K.L. (1991) Antigen retrieval in formalin-fixed, paraffin embedded tissues: an enhancement method for immunohistochemical staining based on microwave oven heating of tissue sections. J. Histochem. Cytochem., 39, 741-748.

24 Takasaki, Y., Deng. J.S. and Tan, E.M. (1981) A nuclear antigen associated with cell proliferation and blast transformation. Its distribution in synchronized cells. J. Exp. Med., 154, 1899-1909.

25 van Dierendonck, J.H., Wijsman, J.H., Keijzer, R., van de Velde, C.J.H. and Cornelisse, C.J. (1991) Cell-cycle related staining patterns of anti-proliferating cell nuclear antigen monoclonal antibodies, Am. J. Pathol., 138(5), 1165-1172. 